\title{
Binding of carbon nanotube to BMP receptor 2 enhances cell differentiation and inhibits apoptosis via regulating bHLH transcription factors
}

\author{
Y Zhang ${ }^{1,2}, Q M^{2}{ }^{2}$ H Zhou ${ }^{2}, K_{\text {Vrijens }}^{3}$, MF Roussel ${ }^{3}$, G Jiang $^{4}$ and B Yan ${ }^{\star, 2,5}$
}

Biomaterials that can drive stem cells to an appropriate differentiation level and decrease apoptosis of transplanted cells are needed in regenerative medicine. Nanomaterials are promising novel materials for such applications. Here we reported that carboxylated multiwalled carbon nanotube (MWCNT 1) promotes myogenic differentiation of mouse myoblast cells and inhibits cell apoptosis under the differentiation conditions by regulating basic helix-loop-helix transcription factors. MWCNT 1 attenuates bone morphogenetic protein receptor (BMPR) signaling activity by binding to BMPR2 and attenuating the phosphorylation of BMPR1. This molecular understanding allowed us to tune stem cell differentiation to various levels by chemical modifications, demonstrating human control of biological activities of nanoparticles and opening an avenue for potential applications of nanomaterials in regenerative medicine.

Cell Death and Disease (2012) 3, e308; doi:10.1038/cddis.2012.48; published online 10 May 2012

Subject Category: Experimental Medicine

Nanotechnology has evolved rapidly and has an impact on nearly every aspect in modern society including medicine. For example, carbon nanotube (CNT) materials have shown promising potentials in drug ${ }^{1}$ and gene delivery, ${ }^{2}$ cancer cell imaging $^{3}$ and regenerative medicine. CNT has been able to direct the differentiation of mouse embryonal carcinoma stem cells ${ }^{4}$ and promote neural stem cell differentiation from human embryonic stem cells. ${ }^{5}$

Adult stem cells, the undifferentiated cells residing in mature organs or tissues, can renew themselves and differentiate to cells of the specialized tissues or organs. Because of the less controversial aspect of their use than embryonic stem cells, the easy accessibility, and their capability to divide in cell cultures, adult stem cells provide valuable cell sources to treat and cure many regenerative diseases. Induction of myogenic differentiation from different adult stem cells is promising to cure diseases like muscular dystrophies, ${ }^{6}$ cardiac myocyte death ${ }^{7}$ and muscle damage. For example, mesenchymal stem cells identified from bone marrow have been successfully used for repairing heart muscle in cardiac ischemia. ${ }^{7,8}$ However, this application is limited by the poor viability of the transplanted cells caused by the pathological milieu and loss of survival signals from matrix attachments and cell-cell interactions. ${ }^{9}$ In order to increase the survival of stem cell grafts, some transgenic strategies (for instance, by engineering stem cells to express AKT, a serine threonine kinase and a powerful survival signal) have been pursued. ${ }^{10}$ In spite of these endeavors, there is still a need to develop strategies to enhance differentiation in a controllable manner and improve the viability of transplanted cells. $\mathrm{C} 2 \mathrm{C} 12$ is a mouse myoblast cell line, which is capable of myogenic or osteogenic differentiations. ${ }^{11}$ In this work, we investigated the myogenic differentiation of $\mathrm{C}_{2} \mathrm{C} 12$ under the effects of carboxylated multiwalled CNT (MWCNT 1) and studied the involved molecular mechanisms. The results demonstrated that MWCNT 1 promoted myogenic differentiation of $\mathrm{C} 2 \mathrm{C} 12$ without using any protein or chemical factor. MWCNT 1 also improved cell survival under the differentiation conditions. These effects were originated from the binding of MWCNT 1 to bone morphogenetic protein receptor 2 (BMPR2), suppressing the BMP signaling pathway and regulating basic helixloop-helix (bHLH) transcription factors involved in differentiation and apoptosis. Based on this mechanistic understanding, we successfully modulated myogenic differentiation of $\mathrm{C} 2 \mathrm{C} 12$ to various levels by surface-chemistry modifications on MWCNTs.

\footnotetext{
${ }^{1}$ School of Pharmaceutical Sciences, Shandong University, Jinan 250100, China; ${ }^{2}$ Department of Chemical Biology and Therapeutics, St. Jude Children's Research Hospital, Memphis, TN 38105, USA; ${ }^{3}$ Department of Tumor Cell Biology, St. Jude Children's Research Hospital, Memphis, TN 38105, USA; ${ }^{4}$ Research Center for Eco-Environmental Sciences, Chinese Academy of Sciences, Beijing 100085, China and ${ }^{5}$ School of Chemistry and Chemical Engineering, Shandong University, Jinan 250100, China

*Corresponding author: B Yan, School of Chemistry and Chemical Engineering, Shandong University, 27 Shanda Nanlu, Jinan 250100, China. Tel: + 86 531 88366232; Fax: + 86531 88380029; E-mail: dr.bingyan@gmail.com

Keywords: carbon nanotube; membrane receptor; BMP signaling; cell differentiation; regenerative medicine

Abbreviations: bHLH, basic helix-loop-helix; BMP, bone morphogenetic protein; BMPR, bone morphogenetic protein receptor; BRE, BMP-responsive element; BSA, bovine serum albumin; ChIP, chromatin immunoprecipitation; CNT, carbon nanotube; DAPI, 4',6-diamidino-2-phenylindole; DM, differentiation medium; DMEM, Dulbecco's minimum essential medium; FITC, fluorescein isothiocyanate; FRET, fluorescence resonance energy transfer; GAPDH, glyceraldehyde-3-phosphate dehydrogenase; GM, growth medium; Id, inhibitor of DNA-binding/differentiation; PLA, proximity ligation assay; MWCNT, multiwalled carbon nanotube; MYH, myosin heavy chain; p-BMPR1A, phosphorylated BMPR1A; RT-PCR, reverse transcription PCR; qRT-PCR, quantitative reverse transcription PCR; TEM, transmission electron microscope; TRITC, tetramethyl rhodamine isothiocyanate; TUNEL, terminal deoxynucleotidyl transferase dUTP nick end labeling

Received 07.2.12; revised 19.3.12; accepted 02.4.12; Edited by H-U Simon
} 


\section{Results}

MWCNT 1 promotes myogenic differentiation and inhibits apoptosis. The physicochemical characterization of MWCNT 1 was summarized in Table 1. MWCNT 1 has an inner diameter of $5-12 \mathrm{~nm}$ and an outer diameter and $30-50 \mathrm{~nm}$. On the basis of the functional group loading $(0.4 \mathrm{mmol} / \mathrm{g})$ as determined by the elemental analysis and measured surface area $\left(500 \mathrm{~m}^{2} / \mathrm{g}\right)$, we estimated that the average density of modification is approximately five functional groups per $10 \mathrm{~nm}^{2}$. At $\mathrm{pH} 7.0$, MWCNT 1 carries negative charges. Its solubility in water and plasma is much better compared with the pristine MWCNT. Inductively coupled plasma mass spectrometry analysis indicated a negligible amount of metal impurities excluding the possibility that they may affect cellular function. ${ }^{12}$

C2C12 can differentiate into adipocytes, muscle cells or osteoblasts under different conditions. It has been reported that $\mathrm{C} 2 \mathrm{C} 12$ cells underwent myogenic differentiation after transventricular injection into the arterial circulation of the murine heart. ${ }^{13}$ MWCNT 1 showed little cytotoxicity at concentrations up to $100 \mu \mathrm{g} / \mathrm{ml}$ (Supplementary Figure S1). To mimic the differentiation microenviroment of transplanted cells, C2C12 cells were incubated in the differentiation medium (DM) to evaluate their myogenic differentiation under the influence of MWCNT 1. C2C12 cells when treated with MWCNT 1 expressed myosin heavy chain (MYH) protein, formed myotubes and showed a dose-dependent increase in fusion index compared with DM controls (Figures 1a-c). These data demonstrated that MWCNT 1 accelerated the myogenic differentiation under the differentiation environment.

Differentiation conditions (low serum) deprived mitogens of cells and caused an increase in apoptotic cells (20-30\%). ${ }^{14}$ Microscopic observation indicated that the cell death was significantly decreased by MWCNT 1 treatment (Figures 1d and e). Terminal deoxynucleotidyl transferase dUTP nick end labeling (TUNEL) assay showed that MWCNT 1 treatment decreased the percentage of TUNEL-positive cells from 23 to about $8 \%$ in $48 \mathrm{~h}$ (Supplementary Figure S2 and Figure 1f).

Table 1 Characterization of MWCNT-COOH

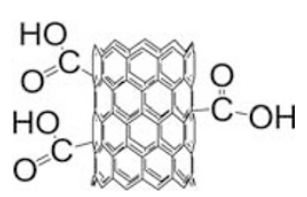

Chemical structure

$$
\begin{aligned}
& \text { Length }(\mu \mathrm{m}) \\
& \text { Zeta potential (mV in H2O) } \\
& \text { Zeta potential (mV in plasma) } \\
& \text { Functional group loading (mmol/g) } \\
& \text { Fe, Al, Cr and Mn (\%) by ICP-MS } \\
& \text { Other } 19 \text { metals (\%) by ICP-MS }
\end{aligned}
$$$$
\text { Diameter }(\mathrm{nm})
$$

The activity of apoptotic effector protein caspase $3^{15}$ dropped to nearly control level (1.2-fold compared with that in growth medium) (Figure 1g). These data showed that MWCNT 1 promotes myogenic differentiation as well as inhibits apoptosis of $\mathrm{C} 2 \mathrm{C} 12$ under the differentiation conditions.

The myogenic differentiation of $\mathrm{C} 2 \mathrm{C} 12$ was coordinated by a family of proteins containing bHLH structures including MyoD, myogenin, myf5, mrf4 and E2A proteins such as HEB, E12 and E47. ${ }^{16}$ The inhibitor of DNA-binding/ differentiation (Id) proteins are negative regulators of myogenic differentiation. ${ }^{17}$ The Id proteins form a complex with myogenic regulatory factors and prohibit their binding to DNA to activate the expression of muscle-specific genes. ${ }^{17}$ We first evaluated whether MWCNT 1 promoted myogenic differentiation by altering functions of these two families of proteins or their interactions.

MWCNT 1 positively regulates functions of bHLH proteins. We first analyzed the effects of MWCNT 1 on myogenic regulatory factors and Id proteins. Because of the functional redundancy of MyoD with $\mathrm{mrf}^{18}$ and myogenin with myf5, ${ }^{19}$ we analyzed the protein levels of two myogenic regulatory factors MyoD and myogenin and one E2A protein HEB. The expression level of MyoD and HEB did not change, whereas the expression of myogenin increased (Figure 2a). In the normal medium, MWCNT 1 treatment decreased the expression of all the three Id genes on both mRNA and protein levels (Supplementary Figure $\mathrm{S} 3 \mathrm{a}$ and Figure $2 \mathrm{~b}$ ). Under the differentiation conditions, MWCNT 1 treatment also downregulated Id1 and Id3 at the mRNA level (Supplementary Figure S3b). MyoD is known as a marker for myogenic commitment and its major function is to induce the expression of myogenin and cell-cycle inhibitors such as p21. ${ }^{16,20}$ MyoD forms a complex with E2A protein and activates the expression of target genes by binding to E-box motifs in the promoter region of these genes. ${ }^{16}$ However, because of their higher affinity to E2A proteins, Id proteins compromise the MyoD-E2A complex formation and block the gene expression by binding to E2A proteins. ${ }^{17}$ The nanotube-induced increase in myogenin expression and decrease in Id proteins expression suggested that MWCNT 1 might abrogate the formation of HEBId complex, thus favoring the formation of HEB-MyoD complex. Co-immunoprecipitation with HEB followed by probing the co-precipitated proteins with anti-ld1 and antiMyoD antibodies confirmed that Id1 downregulation actually promoted the HEB-MyoD complex formation (Figure 2c). In order to further validate that the enhanced myogeninexpression level after MWCNT 1 treatment is indeed caused by the elevated HEB-MyoD complex formation, chromatin immunoprecipitation (ChIP) assay with anti-HEB and antiMyoD antibodies was carried out. The results indicated that MWCNT 1 treatment recruited more HEB-MyoD complex to the E-box region of the myogenin promoter (Figure 2d). As a consequence of the increased DNA binding by HEB-MyoD complex, the activity of the myogenin promoter was increased by six-folds (Figure 2e).

Myogenin triggers the expression of muscle-specific genes by replacing MyoD and forming a dimer with HEB after the initiation of differentiation $(24-48 \mathrm{~h}$ under the 


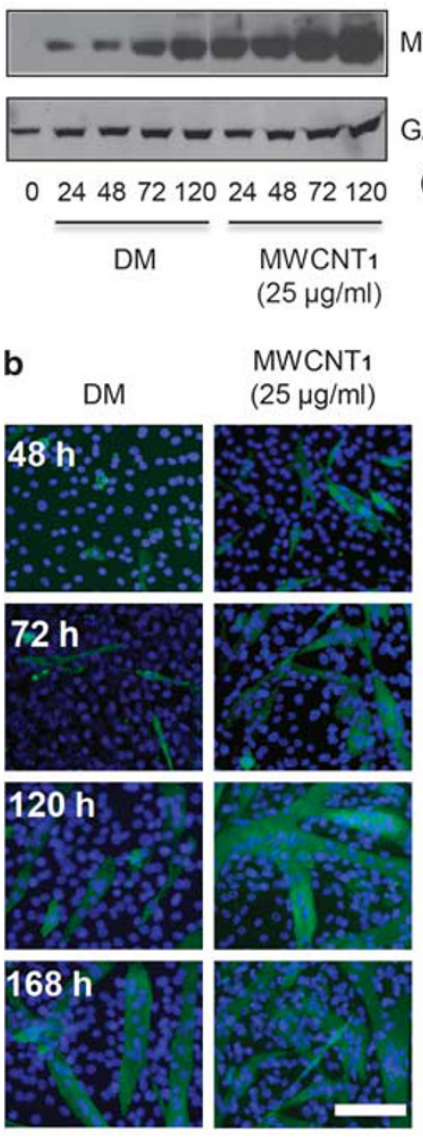

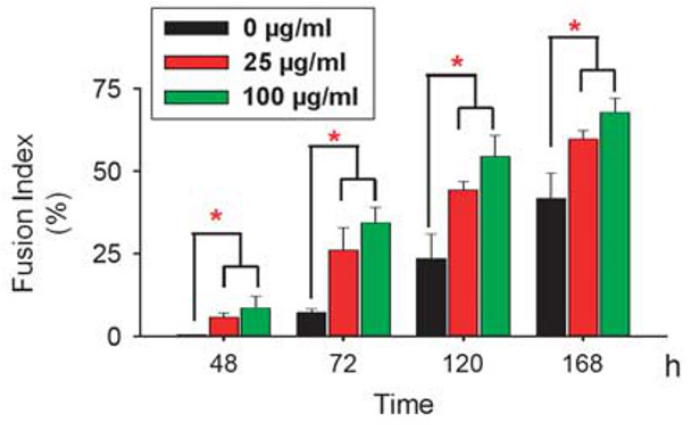

d
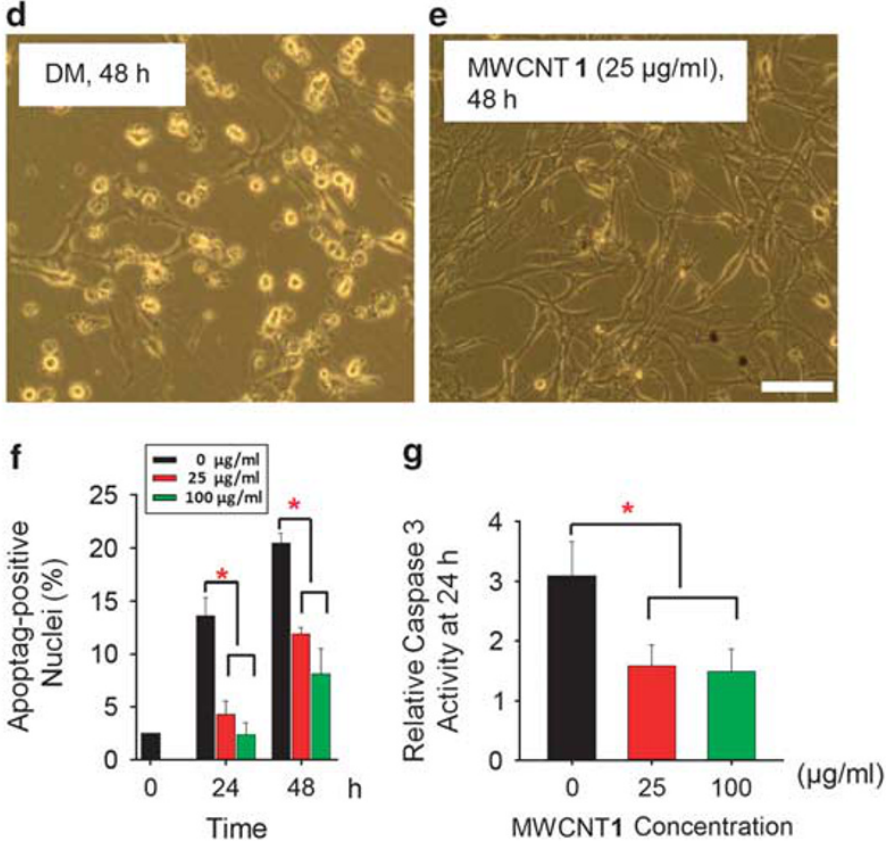

Figure 1 MWCNT 1 promotes $\mathrm{C} 2 \mathrm{C} 12$ differentiation and inhibits apoptosis. (a) Time-dependent MYH protein expression assayed by western blot with anti-MYH antibody. (b) Myotube formation in C2C12 cells cultured in DM or MWCNT $1(25 \mu \mathrm{g} / \mathrm{ml})$ for various time points. Immunocytochemistry was performed with anti-MYH antibody and FITCconjugated secondary antibody (scale bar: $200 \mu \mathrm{m}$ ). (c) Quantitative analysis of time-dependent cell differentiation under MWCNT 1 concentrations of 25 and $100 \mu \mathrm{g} / \mathrm{ml}$ assayed by nuclear fusion index $\left({ }^{*} P<0.05\right.$ ). (d and e) Phase-contrast photomicroscopy revealed cell apoptosis after $48 \mathrm{~h}$ in DM and MWCNT 1 concentration of $25 \mu \mathrm{g} / \mathrm{ml}$. (f) Quantitative analysis of BrdU-positive nuclei. The percentage of BrdU-positive nuclei in $0 \mathrm{~h}$ was also shown. (g) Quantitative analysis of caspase 3 activity. Caspase 3 activity in GM group was normalized to $1.0\left({ }^{\star} P<0.05\right)$. GM, growth medium

differentiation conditions). ${ }^{20}$ A significant increase in HEBmyogenin complex formation after MWCNT 1 treatment was observed (Figure 2c). A subsequent event is the nuclear translocation of myogenin to activate the expression of muscle-specific genes. Immunocytochemistry showed that MWCNT 1 accelerated both the expression and nuclear translocation of myogenin (Figures $2 f$ and $g$ ). Together, these data showed that by negative regulation of $\mathrm{Id}$ proteins, MWCNT 1-enhanced positive regulation of celldifferentiation machinery.

p21 ${ }^{\text {Cip1/waf }}$-mediated apoptosis inhibition. We were also interested in investigating how MWCNT 1 suppressed cell apoptosis. Cdk inhibitors, such as p21 $1^{\text {Cip } 1 / \text { waf }}$ (hereinafter p21), can protect cells from apoptosis, ${ }^{14,21}$ and p21 expression was controlled by the bHLH proteins. ${ }^{22,23}$ We found that MWCNT 1 treatment upregulated the p21 promoter activity (Supplementary Figure S4a) and recruited more HEB-MyoD complex to bind to p21 promoter (Supplementary Figure S4b). Western blot analysis showed an increased expression of p21 from 24 to $72 \mathrm{~h}$ after MWCNT 1 treatment (Figure 3a). On the basis of these results and the previous reports, ${ }^{14,21}$ we hypothesized that the MWCNT 1-induced elevation of p21 expression accounted for the apoptosis suppression. p21 inhibits apoptosis only when it is translocated from nucleus to mitochondrial membrane. ${ }^{24}$ To verify the mitochondrial localization of p21, we labeled mitochondria with a mouse-originated anti-Core II antibody and a Cy3-labeled secondary antibody, and p21 was labeled with rabbitoriginated anti-p21 antibody and a fluorescein isothiocyanate (FITC)-conjugated secondary antibody. Our results showed that p21 proteins were mainly localized in mitochondria in MWCNT 1-treated cells. In the untreated group, p21 proteins resided in the nucleus (Figure $3 b$ ). At the mitochondrial membranes, p21 forms a complex with procaspase 3 and inhibits its activation. ${ }^{25,26}$ The enhanced p21-procaspase 3 
a

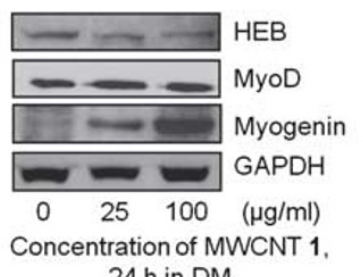

$24 \mathrm{~h}$ in DM

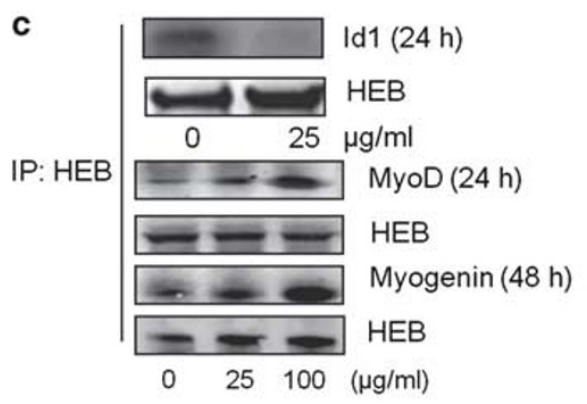

Concentration of MWCNT 1 b

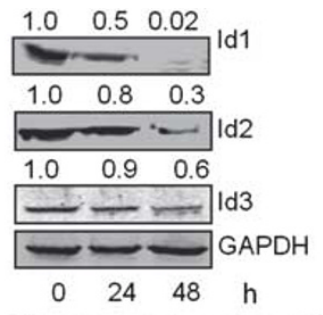

Time in normal medium, 25 $\mu \mathrm{g} / \mathrm{ml}$ MWCNT 1

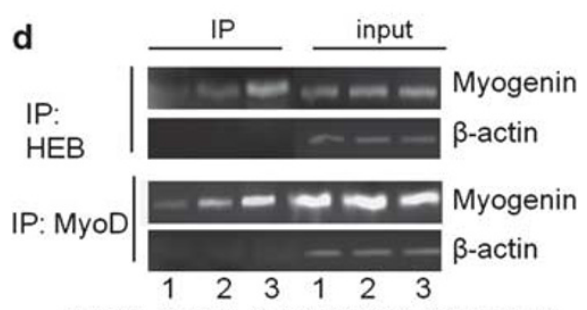

1. GM, 2. DM, 3. MWCNT $1(25 \mu \mathrm{g} / \mathrm{ml})$
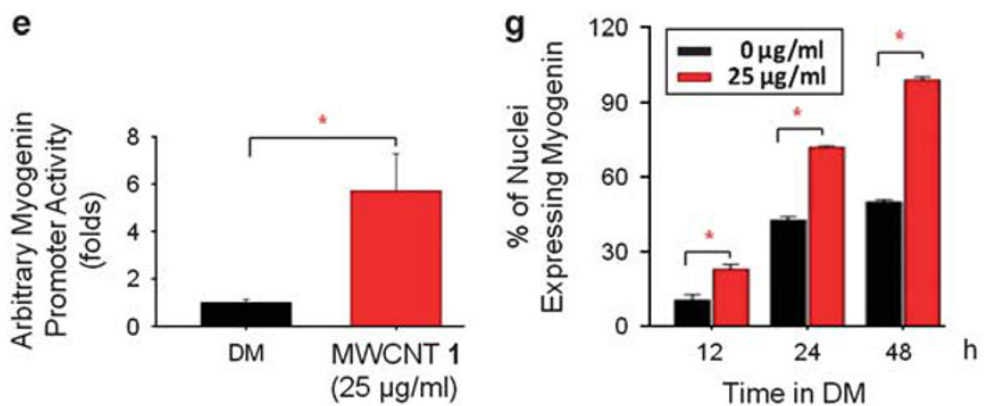

f $12 \mathrm{~h}$ $24 \mathrm{~h}$ $48 \mathrm{~h}$

$$
\text { f }
$$
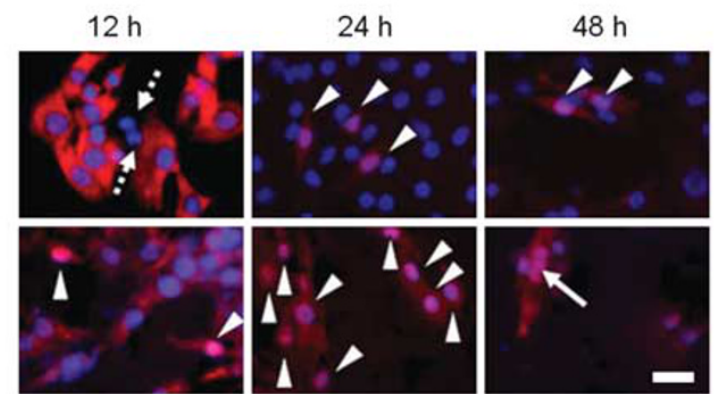

Figure 2 MWCNT 1 positively regulates functions of MyoD and myogenin by inhibiting expression of Id proteins. (a) Effects of MWCNT 1 on the expression of MyoD, myogenin and HEB analyzed by western blots. (b) MWCNT 1 decreased the expression of Id proteins. (c) MWCNT 1 caused a decrease in HEB-Id complex formation and an increase in HEB-MyOD and HEB-myogenin. Protein complex formations were analyzed by co-immunoprecipitation with anti-HEB antibody followed by probing the coprecipitated proteins with different antibodies after MWCNT 1 treatment. (d) MWCNT 1 recruiting HEB-MyoD complexes to E-box motifs in the promoter of myogenin gene assayed by chromatin immuoprecipitation (ChIP) with anti-HEB and anti-MyoD antibodies. Total DNA before immunoprecipitation was used as input controls and $\beta$-actin was used as a control for specificity (Supplementary Information for details). (e) Myogenin promoter activity enhanced by MWCNT 1. C2C12 was transfected with constructs containing firefly luciferase gene driven by myogenin promoter and the luminescence intensity was measured after treatment for $48 \mathrm{~h}$. The luminescence intensity in DM was normalized to 1.0. (f) Myogenin expression and distribution in C2C12 cultured in DM or MWCNT 1 for various times. Myogenin-negative cells were indicated by arrows with dotted line and cells with nuclear translocation of myogenin were shown with arrow heads. Fusion of myogenin-positive nuclei was indicated by arrows with solid line. Immumnocytochemistry was performed with anti-myogenin antibody and Cy3-conjugated secondary antibody. (scale bar: $50 \mu \mathrm{m}$ ). (g) Quantitative analysis of nuclei expressing myogenin at different time points $\left({ }^{*} P<0.05\right)$

complex formation was observed in a co-immunoprecipitation assay (Figure 3c). MWCNT 1 also inhibited caspase 3 activity (Figure 2f). Therefore, our findings suggested that upregulation of the expression of p21 proteins was at least one mechanism to protect cells from apoptosis under the differentiation conditions.
The above data demonstrated that MWCNT 1's downregulation of Id protein levels has a critical role in promoting myogenic differentiation and inhibiting apoptosis of $\mathrm{C} 2 \mathrm{C} 12$. The Id proteins are the targets of the BMP signaling pathway. ${ }^{27}$ We have reported that CNTs inhibit the BMP signaling pathway ${ }^{28}$ and this was confirmed by 

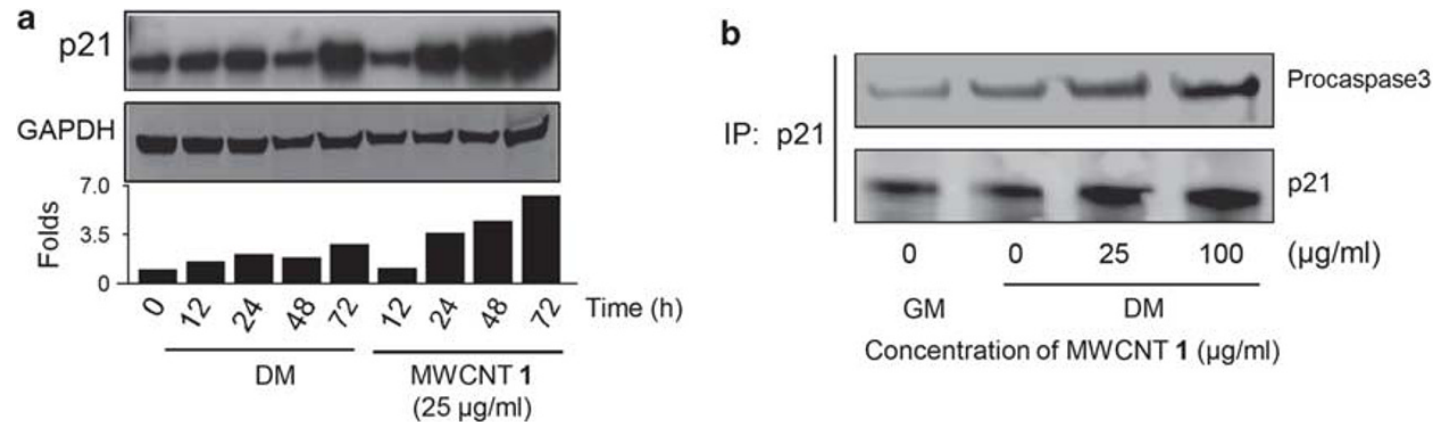

Concentration of MWCNT $1(\mu \mathrm{g} / \mathrm{ml})$
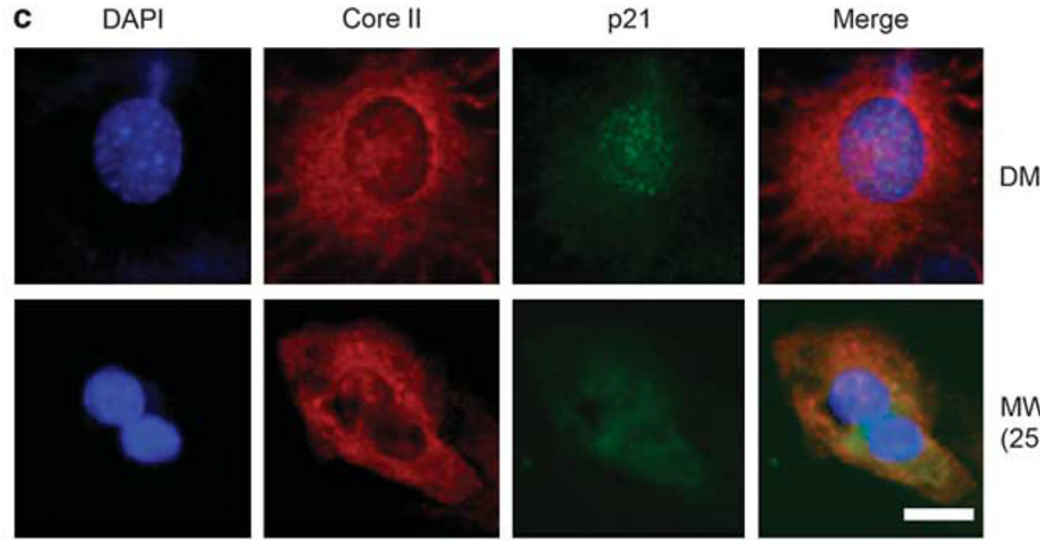

MWCNT 1

$(25 \mu \mathrm{g} / \mathrm{ml})$

Figure 3 Induced p21 protects cells from apoptosis. (a) Time-dependent p21 expression analyzed by western blot. The protein expression level was quantified by the band density using Image $\mathrm{J}$ method and the ratio between $\mathrm{p} 21$ and GAPDH bands was plotted after normalizing that in 0-h group as 1.0. (b) MWCNT 1-induced mitochondrial translocation of p21 after treatment for $48 \mathrm{~h}$. p21 proteins only located in the nuclei in DM group, whereas translocated to mitochondria after MWCNT 1 treatment. Mitochondria and p21 were detected simultaneously by mouse-originated anti-Core II and rabbit-originated anti-p21 antibodies. Cy3- and FITC-conjugated secondary antibodies were used. Scale bar, $5 \mu \mathrm{m}$. (c) Complex formation between p21 and procaspase 3. Cell extracts after MWCNT 1 treatment for $24 \mathrm{~h}$ were co-immunoprecipitated with anti-p21 antibody followed by probing with anti-p21 and anti-procaspase 3 antibodies

an independent group. ${ }^{29}$ Here we found that MWCNT 1 also inhibited Id protein expression by suppressing the BMP signaling pathway. In order to gain further understanding of interplays between MWCNT 1 and the BMP signaling pathway, we investigated the further details in this context.

MWCNT 1 perturbs the phosphorylation of BMPR1. BMP signaling is suppressed when the initial membrane-receptor activation or any of the following signal transduction steps is partially blocked. ${ }^{30}$ In order to reveal how MWCNT 1 blocked BMP signaling, we examined the effects of MWCNT 1 on individual signaling steps. ${ }^{31}$ We first analyzed the phosphorylation of Smad1/5/8. Western blot indicated that while the level of Smad1/5/8 was unchanged, MWCNT 1 treatment decreased their phosphorylation level (Figure 4a), suggesting that Smad $1 / 5 / 8$ phosphorylation or an upstream step was affected. In cells, Smad1/5/8 was phosphorylated by activated BMPR1. In order to clarify whether MWCNT 1 affected any step downstream of BMPR1 phosphorylation, a transgenic cell line $\mathrm{C} 33 \mathrm{~A}-2 \mathrm{D} 2$ containing firefly luciferase reporter driven by Id1 promoter was transiently transfected with constitutively active forms of the type 1 BMP receptor ALK2 and ALK3 (BMPR1A) to generate C33A-2D2-ALK 2 and C33A-2D2-ALK 3 cells. These constructs mimic the phosphorylated BMPR1 and are able to constitutively phosphorylate Smad1/5/8 and transduce intracellular signals. ${ }^{30}$ Incubation of both the transfected cell lines with MWCNT 1 at various concentrations for different times showed no dose-dependent inhibition on ld1 promoter activity, whereas the specific Smad1/5/8 inhibitor dorsomorphin did (Figures $4 \mathrm{c}-\mathrm{f}$ ). These results suggested that MWCNT 1 did not interfere with any step downstream of BMPR1.

Phosphorylation of BMPR1 by BMPR2 after ligand binding is the first step to trigger the intracellular BMP signaling cascade. $^{31}$ In order to investigate whether MWCNT 1 interferes with the phosphorylation process of BMPR1, the phosphorylated BMPR1A in whole-cell extract was determined after co-immunoprecipitation with its antibody. The data showed that MWCNT 1 strongly suppressed BMP4-induced phosphorylation of BMPR1A (Figure 4b), suggesting that MWCNT 1 inhibited BMPR1 phosphorylation by BMPR2.

MWCNT 1 binds to BMPR2 and suppresses BMP signaling process. The suppression of BMPR1 phosphorylation by MWCNT 1 suggested that its target might be membrane-bound BMP receptors. Under the transmission electron microscope (TEM), MWCNT 1 bound to cell surface or was endocytosed into cells with continued membrane interactions (Figures $5 \mathrm{a}$ and $\mathrm{b}$ ). We first investigated the spatial proximity of MWCNT 1 with BMPRs. To do this, we conjugated mouse IgG to MWCNT 1. By an in situ proximity ligation assay (PLA) ${ }^{32}$ using rabbit antibodies to BMPR1A 
a

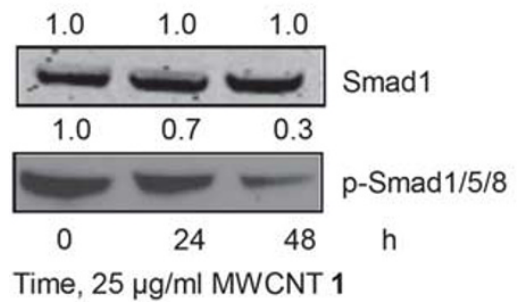

Time, $25 \mu \mathrm{g} / \mathrm{ml}$ MWCNT 1
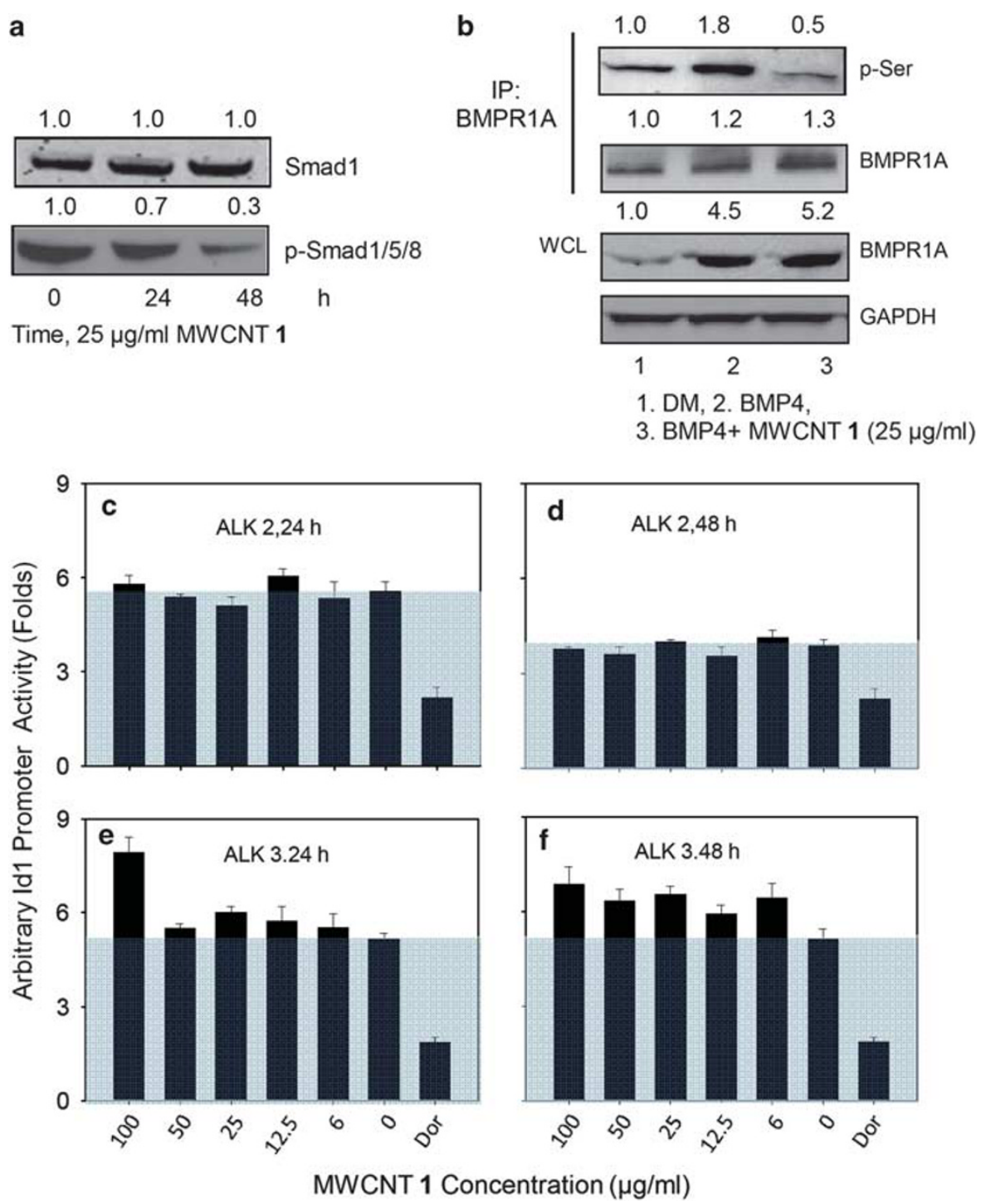

Figure 4 MWCNT 1 inhibits BMP signaling by blocking phosphorylation of BMPR1A. (a) Inhibition on BMP signaling by MWCNT 1 shown by decreasing phosphorylation of Smad1/5/8. (b) MWCNT 1 decreased phosphorylation level of BMPR1A. Whole-cell extract $(200 \mu \mathrm{g})$ from C2C12 cells treated with MWCNT $1 \mathrm{and} / \mathrm{or}$ BMP4 $(25 \mathrm{ng} / \mathrm{ml})$ for $6 \mathrm{~h}$ was co-immunoprecipitated with anti-BMPR1A antibody followed by probing with anti-phosphorylated-Serine (p-Ser) and anti-BMPR1A antibodies. The level of BMPR1A in whole-cell lysate was also probed. (c-f) MWCNT 1 did not affect Id1 promoter activity induced by constitutively active BMP receptors. Amino-acid mutations in wild-type BMP 1 receptors ALK2 and ALK3/BMPR1A produced ligand-independent activation of BMP signaling in C33A-2D2-ALK2 and C33A-2D2-ALK3 cells, which also contain firefly luciferase genes driven by Id1 promoter. The Id1 activity in empty vector-transfected cells was normalized as 1.0. Dorsomorphin (25 $\mu \mathrm{M})$, a specific inhibitor of the Smaddependent BMP signaling pathway was used as positive control

and BMPR2, we detected a close proximity between MWCNT 1 and BMPR2 (10.6 PLA signals per nuclear, compared with 20.5 PLA signals per nuclear in positive control of BMPR1A/BMPR2 and 1.8 PLA signals per nuclear in negative control of bovine serum albumin (BSA)-conjugated MWCNT 1 (Supplementary Figures S5a and b)) other than with BMPR1A (4.0 PLA signals per nuclear) (Figures $5 \mathrm{c}$ and $\mathrm{d}$ ). This was likely due to a direct binding between MWCNT 1 and BMPR2. In order to substantiate MWCNT 1/ BMPR2 binding, we also determined fluorescence resonance energy transfer (FRET) between fluorescent-labeled MWCNT 1 and BMPR2. MWCNT 1 was labeled with FITCconjugated BSA (FITC-BSA) and BMPR2 was labeled with tetramethyl rhodamine isothiocyanate (TRITC)-conjugated secondary antibody. FRET acceptor bleaching method ${ }^{33}$ measures the donor 'de-quenching' in the presence of acceptor by comparing donor fluorescence intensity before and after destroying the acceptor by photobleaching. If FRET is initially present, a resultant increase in donor fluorescence will occur on photobleaching of the acceptor. We found that photobleaching TRITC resulted in an increase in the FITC intensity with an efficiency of $15 \sim 20 \%$ (Figures $5 i-n$ ). This increased efficiency is comparable to that reported in interaction between two fluorescent proteins; ${ }^{34}$ hence this result confirmed the binding between MWCNT 1 and BMPR2. This binding event abrogated the BMPR1ABMPR2 heterodimer formation as shown also by PLA using antibodies to BMPR1A and BMPR2 after BMP4 

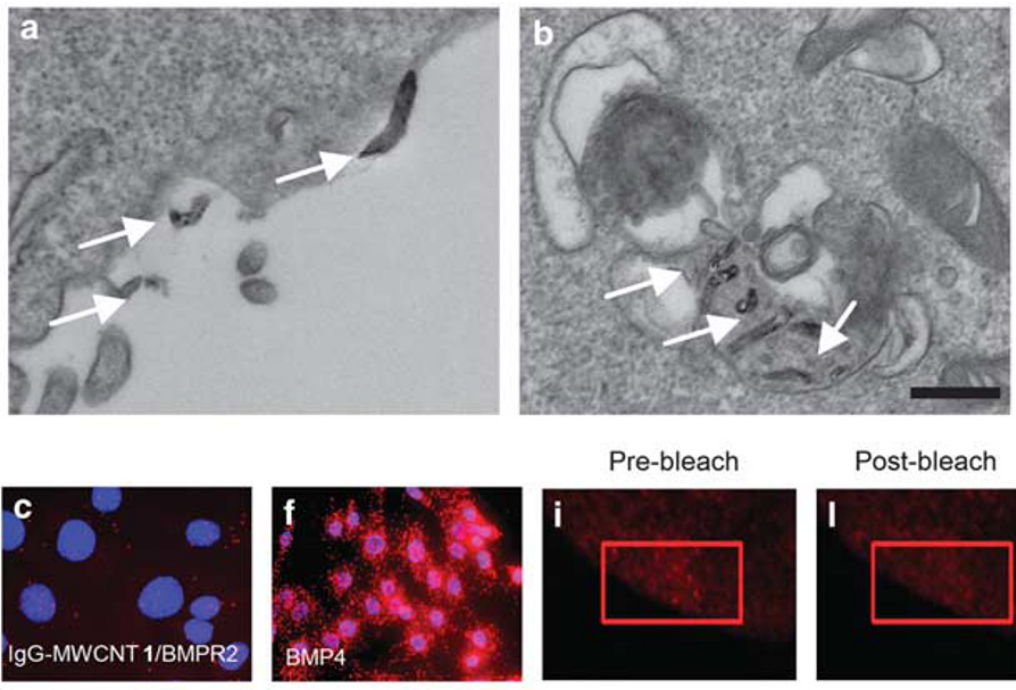

Post-bleach
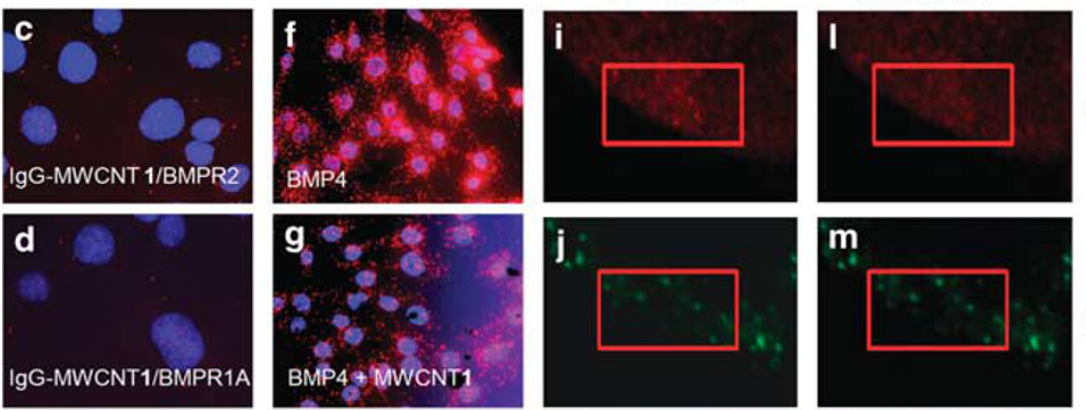

TRITC
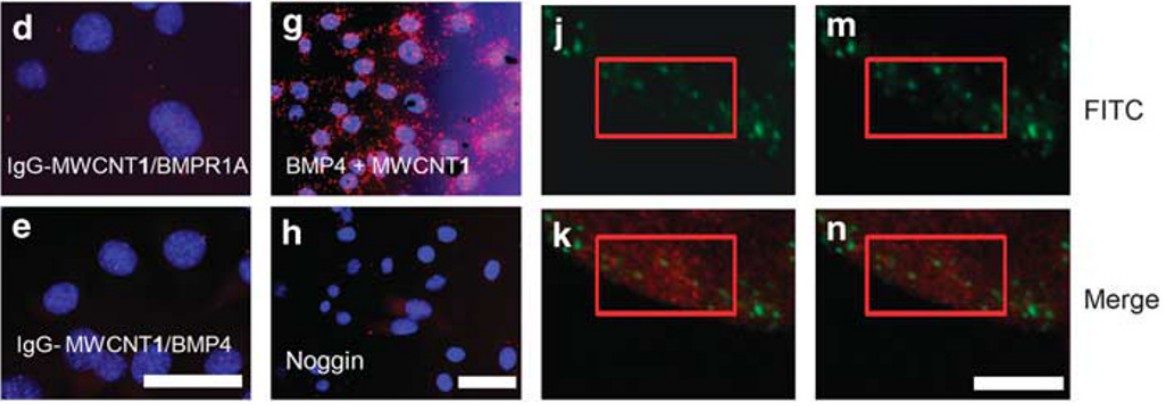

Figure 5 MWCNT 1 blocks phosphorylation of BMPR1A by binding to BMPR2. (a and $\mathbf{b}$ ) TEM images show MWCNT 1s (arrows) bound to cell membranes or in endosomes. C2C12 cells were incubated with MWCNT $1(25 \mu \mathrm{g} / \mathrm{ml})$ for $2 \mathrm{~h}$ before fixation. Scale bar, $100 \mathrm{~nm}$. (c-h) MWCNT 1 has a close proximity with BMPR2 and interferes with BMPR1A-BMPR2 complex formation assayed by in situ PLA. In (c-e) MWCNT 1 was conjugated with mouse lgG, and protein pairs between IgG with rabbit BMPR2 (c), BMPR1A (d) and BMP4 (e) antibodies were determined. PLA signals were shown in red, and nuclei were stained blue by DAPI. (f-h) BMPR1A-BMPR2 complex formation was assayed by in situ PLA after addition of BMP4 (f), BMP4 with MWCNT 1 (g) and BMP4 with noggin (h). C2C12 cells were treated with MWCNT 1 (25 $\mu \mathrm{g} / \mathrm{ml})$ or noggin $(200 \mathrm{ng} / \mathrm{ml})$ for $2 \mathrm{~h}$ followed by BMP4 $(25 \mathrm{ng} / \mathrm{ml})$ treatment for $1 \mathrm{~h}$ before fixation. Scale bars, $50 \mu \mathrm{m}$. (i-n) MWCNT 1 (labeled by FITC) closely associates with BMPR2 (labeled by TRITC) as detected by FRET. A region in the red rectangle was photobleached at $543 \mathrm{~nm}$ (TRITC channel) for 50 exposures and images were taken in FITC $(488 \mathrm{~nm})$ and TRITC $(543 \mathrm{~nm})$ channels before and after bleaching. Scale bars, $50 \mu \mathrm{m}$

treatment (Figures $5 \mathrm{f}-\mathrm{h}$ ). The interruption of the formation of BMPR1A-BMPR2 heterodimer markedly suppressed the BMP4-induced phosphorylation of BMPR1A as analyzed by immunoprecipitation (Figure $4 \mathrm{~b}$ ). We also found that MWCNT 1 in culture system neither adsorbed BMP4 ligand (Figure 5e) nor affected their binding to BMPRs (Supplementary Figures S5c-f). These data demonstrated that MWCNT 1 affected the BMP signaling pathway by binding to BMPR2 and compromising its signaling function.

Our finding can be summarized into a working model (Figure 6). By binding to BMPR2 and inhibiting the phosphorylation of BMPR1, MWCNT 1 downregulates the phosphorylation of Smad1/5/8 and reduces the expression of Id proteins. The decrease in Id proteins expression enhances the formation of HEB-MyoD complex, which in turn promotes the expression of myogenin and p21. Myogenin forms complex with HEB to activate the differentiation-specific genes (e.g., MYH) and leads to myogenesis. p21 proteins translocate to mitochondria to bind and inhibit the activation of procaspase 3, thereby suppressing apoptosis.
Fine tuning of cell differentiation by surface modifications on MWCNT 1. Biological perturbations by nanoparticles can be attributed to their size, shape, structure and surface properties. ${ }^{35}$ When the size, shape and structure of nanoparticles are kept the same, their surface chemistry will dictate the surface properties such as hydrophobicity, stereochemistry and charges. The altered surface properties of CNTs determine their interactions with proteins and other biological molecules. ${ }^{36}$ We hypothesized that the interactions of CNTs with BMPRs might be modulated by their surface chemistry. We therefore examined a diverse array of surfacemodified MWCNTs, which contains 84 members (MWCNT $1-84)^{37}$ for their effects on the activation of BMPRs as indicated by Id1 promoter activity in C33A-2D2 cells. MWCNTs with diverse surface-chemistry modifications generated various Id1 promoter activations (Supplementary Figure S6 and Figure 7b). To explore whether we could tune cell differentiation by modulating BMP signaling activation, we further investigated MWCNTs 6, 7, 11, 12, 20 and 43 (Figure 7a) for their effects on cell signaling and differentiation. First, we found that they enter cells in a similar manner 


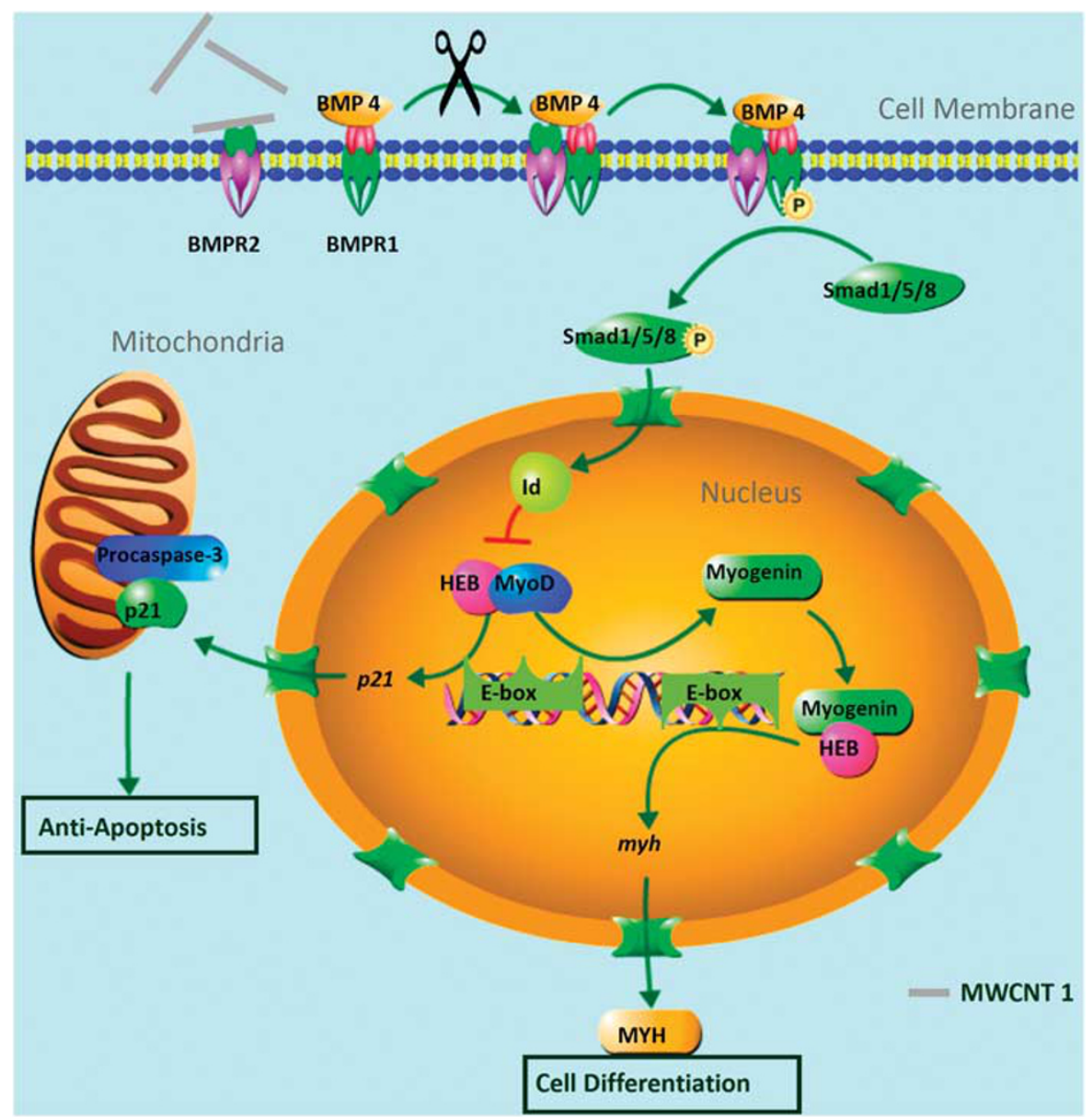

Figure 6 A schematic diagram showing the molecular interactions involved in MWCNT 1-enhanced cell differentiation and inhibition of apoptosis. MWCNT 1 binds to BMP receptor 2 (BMPR2) and inhibits the heterodimer formation between BMPR1 and BMPR2, blocking the phosphorylation of BMPR1. This consequently attenuates the expression of Id proteins, which are members of the negative $\mathrm{HLH}$ family of proteins. Lower Id protein levels reduced their ability to inhibit complex formation between ubiquitous E-protein (HEB) and tissue-specific E-proteins (MyoD and myogenin). These positive HLH protein complexes activate the expression of differentiation-specific genes (myogenin and MYH) and p21 by binding to E-box motif in their promoter region. p21 translocated from nuclear to mitochondria, where it binds to procaspase 3 and inhibits cell apoptosis

as MWCNT 1 as shown by TEM (Supplementary Figure S7a). Similar to MWCNT 1, they did not inhibit caALKinduced Id1 activation in C33A-2D2-ALK2 or C33A-2D2ALK3 cells (Supplementary Figure S7b). These MWCNTs also showed various inhibitions on BMPR1A phosphorylation (Figure 7e). Furthermore, they downregulated phosphorylation of Smad1/5/8 and the expression of Id proteins in the same order (Figure 7e). These data strongly showed that surface-chemistry modifications conferred different modulations on BMPR and caused different levels of suppression on the BMP signaling pathway. Therefore, this approach is promising for fine tuning of cell differentiation through modulating BMP signaling to a desired level. To test this possibility, we analyzed the differentiation profile of $\mathrm{C} 2 \mathrm{C} 12$ cells into myotubes. Our data showed that the differentiation of $\mathrm{C} 2 \mathrm{C} 12$ was regulated to various levels as shown by the inversely correlated myogenin promoter activity (Figure 7c) and different expression levels of both myogenin and the differentiation-marker $\mathrm{MYH}$ proteins (Figure 7e). Expression of the apoptosis-inhibitor p21 was also regulated (Figure 7e). As a quantitative measure for terminal differentiation, myotube formation and the nuclear fusion index were also modulated to various controllable levels (Figures $7 f$ and $d$ ).

\section{Discussion}

Rapid and controllable induction of differentiation and decreasing cell apoptosis are both desired attributes of medicinal agents in regenerative medicine. These two aims have been sought out by various strategies ${ }^{10,38}$ without much success. ${ }^{39}$ Nanomaterials hold enormous promises in this aspect because they exhibit suitable physical characteristics and they are able to mimic surface properties of natural tissues. ${ }^{40}$ Therefore, the molecular understanding of the effects of nanoparticle on stem cell differentiation is critical to fully develop their application potential.

In a previous study, ${ }^{41}$ incubation of CNT with cell lysate enhanced protein binding and MS analysis revealed that CNT bound to murine scavenger receptor macrophage receptor with collagenous structure in addition to other proteins. 

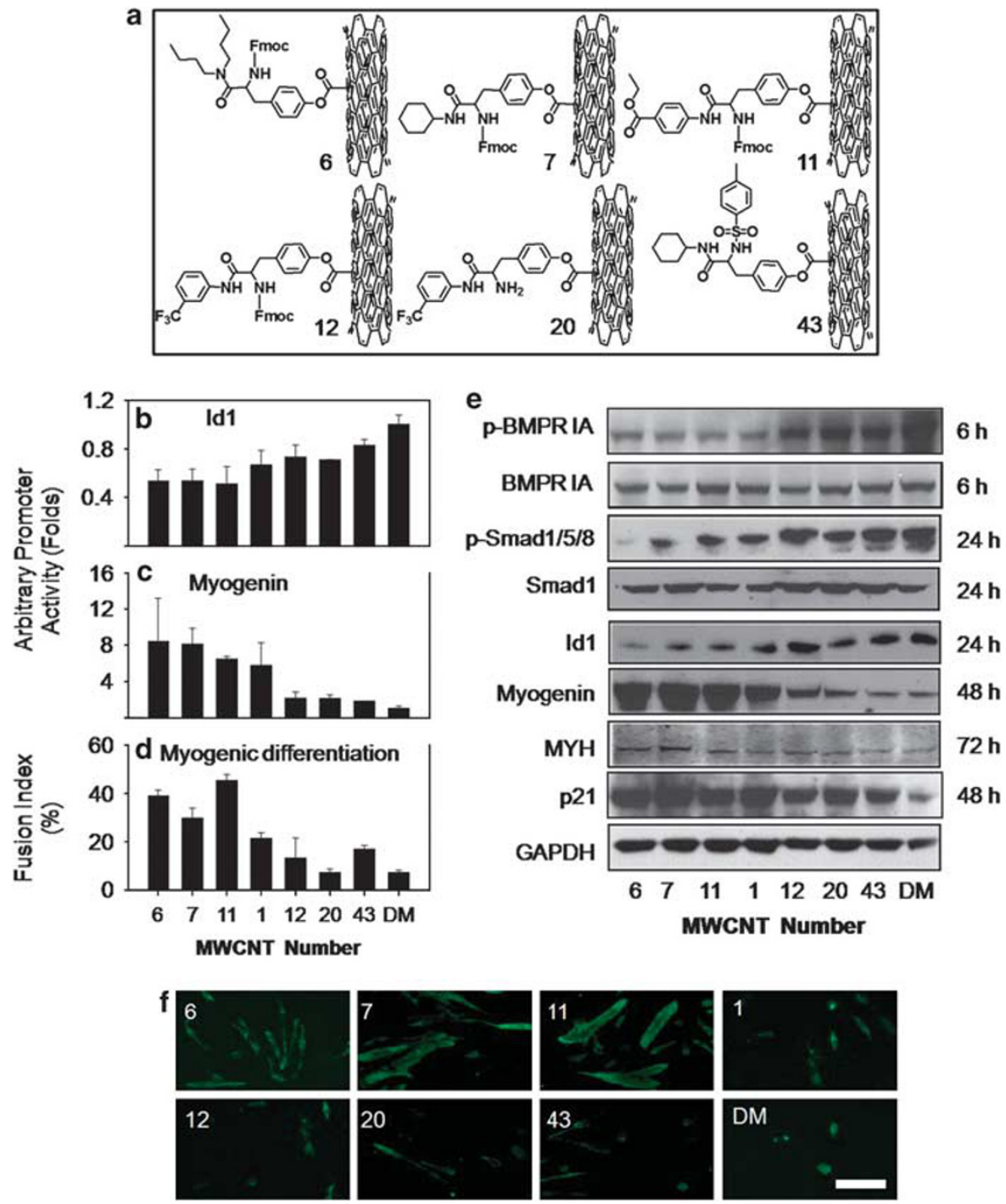

Figure 7 Surface-modified MWCNTs' fine-tune cell differentiation. (a) Chemical structures of CNTs with differently modified surfaces. (b and c) Variable activation of MWCNTs $(25 \mu \mathrm{g} / \mathrm{ml})$ on Id1 promoter (b) and myogenin promoter (c) after treatment for 24 and $48 \mathrm{~h}$, respectively. (d) Effects of MWCNTs on terminal myogenic differentiation of $\mathrm{C} 2 \mathrm{C} 12$ evaluated by nuclear fusion index. MWCNTs with more intense inhibition of Id1 promoter showed higher capability to promote nuclear fusion. (e) Western blot of proteins involved in BMP signaling, cell differentiation and anti-apoptosis. For phosphorylated BMPR1A, whole-cell extracts $(200 \mu \mathrm{g})$ from C2C12 cells treated with MWCNTs $(25 \mu \mathrm{g} / \mathrm{ml})$ and BMP4 $(25 \mathrm{ng} / \mathrm{ml})$ were immunoprecipitated with BMPR1A antibody followed by immunoblotting with an antibody to p-Ser. The level of BMPR1A in C2C12 whole-cell extracts was also probed. For phosphorylated Smad1/5/8, Smad1 and Id1 protein assays, BMP4 $(25 \mathrm{ng} / \mathrm{ml})$ was added to DM simultaneously with MWCNTs to stimulate BMP signaling. The treatment time is also indicated. (f) Representative images showing differential myotube formation after treatment with MWCNTs $(25 \mu \mathrm{g} / \mathrm{ml})$ for $72 \mathrm{~h}$. Immunocytochemistry was performed using MYH antibody and FITC-conjugated secondary antibody (scale bar: $100 \mu \mathrm{m}$ )

Our study provides the evidence that nanoparticles bound to cell-membrane receptors in live cells. Discoveries from this work in combination with previous reports demonstrate how CNTs alter cell functions such as differentiation and apoptosis (Figure 6). The binding of CNTs to BMPR2 weaken the interactions between BMPR2 and BMPR1 and inhibited BMPR1 activation. Such weakening is propagated through the BMP signaling pathway as shown by a downregulation of Smad phosphorylation, Smad nucleus translocation and Id protein expression. Reduced Id expression in cell nucleus changes the regulation of $\mathrm{HLH}$ transcription factors and upregulated cell-differentiation genes and p21, which suppresses cell apoptosis. The combined effect is the enhanced cell myogenic differentiation.
The driving forces for CNTs/protein binding are likely electrostatic, hydrophobic and $\pi-\pi$ stacking interactions. ${ }^{42}$ Such interactions are probably not specific. In fact, CNTs perturbed cell genome by up- and downregulation of more than 400 genes and the BMP pathway is only one of the top ten most-affected signaling pathways. ${ }^{28}$ However, one significant finding from this work is the identification that perturbations on the BMP signaling pathway are resulted from interactions of CNT with BMPR2. On the basis of this finding, chemical modifications on CNTs to alternate its interactions with BMPR2 become possible. By carrying out chemical modifications on CNT surface, we successfully modulated myogenic differentiation of $\mathrm{C} 2 \mathrm{C} 12$ to various levels by controlling CNT-BMPR2 interactions. Chemical basis for 
such regulation was explored by analyzing the relationships between various structural parameters of CNTs' surface molecules and the Id1 promoter activities. Preliminary studies showed that molecular surface areas and polar surface areas exhibited some correlations with the effects of CNTs on BMP signaling. However, the correlation was not very tight, suggesting that more complex factors such as other molecular and CNT interactions were also involved in the regulation of cell differentiation.

Although the biological impacts of nanomaterials are mostly unknown, and some effects are found to be harmful, this work points out that beneficial effects can be initiated by CNTs. This investigation characterized in molecular terms how CNTs promote cell myogenic differentiation by binding to BMPR2 and suppress BMP signaling. Furthermore, we successfully modulated effects of CNTs on differentiation, modifying surface chemistry on CNTs. By this result, we demonstrate the human control of the biological impacts of nanomaterials and open an avenue for the applications of nanomaterials in regenerative medicine.

\section{Materials and Methods}

Materials, cell lines, reagents and antibodies. MWCNT 1 and the combinatorial array of surface-modified MWCNTs were prepared as reported. ${ }^{37}$ Stock solutions of MWCNTs $(1 \mathrm{mg} / \mathrm{ml})$ in $\mathrm{ddH}_{2} \mathrm{O}$ was prepared and sterilized at $121^{\circ} \mathrm{C}$ for $30 \mathrm{~min}$ and sonicated before use.

C2C12 cells $<20$ generations were grown in growth medium (Dulbecco's minimum essential medium (DMEM) medium supplemented with $20 \%$ fetal bovine serum) and were placed in DM (DMEM medium supplemented with $2 \%$ horse serum) when culture reached $80 \%$ of confluence $(t=0 \mathrm{~h})$. C33A-2D2 was constructed using human cervical carcinoma cell line C33A. Single-cell clones from C33A that responded to human recombinant BMP4 were selected after they were transfected with a multimerized BMP-responsive element (BRE) from the mouse Id1 promoter linked to the firefly luciferase gene (pGL4-BRE-Luc). The $\mathrm{EC}_{50}$ value for BMP4-induced specific BRE-mediated activity was $1 \mathrm{ng} / \mathrm{ml}$. The control C33A line expressing the pGL4-luciferase vector only (C33A-empty vector) was also constructed as a control for all the assays.

Constitutive active ALK2 and ALK3 constructs were gifts from Paul B Yu, Harvard Medical School. Myogenin-luciferase and p21-luciferase constructs were gifts from Michael A Rudnicki, Ottawa Health Research Institute, and Carme Gallego, Universitat de Lleida.

Lipofectamine 2000 Transfection Reagent, Opti-MEM I Reduced-Serum Medium, and RIPA Buffer $(10 \times$, no. 9806) were purchased, respectively, from Invitrogen (Grand Island, NY, USA) and Cell Signaling (Danvers, MA, USA). The luciferase assay system (E1500) and the ChIP assay kit (no. 17-295) were purchased, respectively, from Promega (Madison, WI, USA) and Millipore (Billerica, MA, USA). Caspase3/CPP32 Colorimetric Assay Kit (k106-100) was purchased from BioVision (Milpitas, CA, USA).

Goat anti-mouse and goat anti-rabbit secondary antibodies (no. 926-32220 and 926-32221) used for western blot analysis are products of LI-COR Biosciences (Lincoln, NE, USA). All the fluorescent-labeled secondary antibodies used for immunocytochemistry were commercial, obtained from Jackson ImmunoResearch (West Grove, PA, USA). Primary antibodies used in in situ PLA including rabbit antibodies to BMP4 (N-term AP1715a), BMPR1A (C-term, AP2004b) and BMPR2 (N-term, AP2006a) were purchased from Abgent (San Diego, CA, USA). Mouse antibody to BMPR2 (CP 10368) and BMP4 (PA003869-CB12470) were purchased, respectively, from Cell Application Inc. (San Diego, CA, USA), BD Pharmingen (San Jose, CA, USA), and Syd Labs (Boston, MA, USA). MyoD (554130) and myogenin (556358) were commercial, obtained from BD Pharmingen. HEB (A-20), MYH (H-300), p21 (H-164), BMPR-IA (H-60), caspase 3 (3CSP03) and phosphorylated-serine (16B4) antibodies, Protein A/G PLUS-Agarose Immunoprecipitation Reagent (sc-2003), normal mouse IgG (sc-2025) and normal rabbit IgG (sc-2027) are products of Santa Cruz Biotechnology, Inc. (Santa Cruz, CA, USA). Antibodies to phospho-Smad1 (Ser463/465)/Smad5 (Ser463/465)/ Smad8 (Ser426/428) (no. 9511) was from Cell Signaling. Smad1/5/8/9 antibody (ab72504) was from Abcam (Cambridge, MA, USA). Glyceraldehyde-3-phosphate dehydrogenase (GAPDH; G9545) antibody was purchased from Sigma-Aldrich (St. Louis, MO, USA). The Id1 (BCH-1/37-2-50), Id2 (BCH-3/9-2-8-50) and Id3 (BCH-4/6-1-50) antibodies were from BioCheck (Foster City, CA, USA). Complex III subunit Core 2 monoclonal antibody (MS304-SP) was commercial, obtained from MitoSciences (Eugene, OR, USA).

Immunocytochemistry. For immunocytochemistry assays, cells were seeded on $22 \times 22-\mathrm{mm}^{2}$ cover slips (Corning Life Sciences, Tewksbury, MA, USA) and treated with poly-D-lysine. After fixing with cold $4 \%$ paraformaldehyde in PBS for 15 min and membrane permeabilization with $0.25 \%$ Triton X-100 for $10 \mathrm{~min}$, cells were blocked with $1 \%$ BSA in PBS containing $0.5 \%$ Tween-20 for $30 \mathrm{~min}$ followed by $1 \mathrm{~h}$ incubation with primary antibodies and $1 \mathrm{~h}$ incubation with FITC- or cy3-conjugated secondary antibodies at room temperature. Cells were rinsed and mounted on cover slips with mounting medium containing 4',6-diamidino-2-phenylindole (DAPI; Vector Lab, Burlingame, CA, USA). Fluorescence images were taken using a Zeiss (Peabody, MA, USA) LSM 510 confocal microscope with a $\times 40$ objective lens.

Calculation of nuclear fusion index. The nuclear fusion index was calculated by the number of nuclei in cells containing two or more nuclei/total nuclei $\times 100 \%$. For each experiment, 300-500 nuclei were counted.

Primers for PCR. Id1, forward: 5'-CGCTGCAGGCCCTAGCTGTT- 3 ', reverse: 5'-TGGAACACATGCCGCCTCGG-3' (391 bp); Id2, forward: 5'- GCAGATCGCC CTGGACTCGC-3', reverse: $5^{\prime}$-GGCCGGAGAACGACACCTGG-3' (376 bp); Id3, forward: $5^{\prime}$-CTACGAGGCGGTGTGCTGCC-3', reverse: $5^{\prime}$-CTGCGTTCGGGAGG TGCCAG-3' (329 bp); and $\beta$-actin, forward: $5^{\prime}$-AAATCGTGCGTGACATCAAA-3', reverse: $5^{\prime}$-AGAAGGAAGGCTGGAAAAGA-3' (180 bp). Primers for ChIP assay, p21, forward: $5^{\prime}$-ACAGTTGGTCAGGGACAGACCCA-3', reverse: $5^{\prime}$-TCTCGGCT GCTGCAGTTGG-3' (305 bp); myogenin, forward: $5^{\prime}$-GAATCACATGTAATCCAC TGGA-3', reverse: 5'-ACACCAACTGCTGGGTGCCA-3' (180 bp) (E-box motif sequences highlighted by red); and $\beta$-actin, forward: $5^{\prime}$-AAATCGTGCGTGACATC AAA-3' ${ }^{\prime}$, reverse: $5^{\prime}$-AGAAGGAAGGCTGGAAAAGA-3' (180 bp).

Semi-quantitative reverse transcription PCR (RT-PCR) and quantitative RT-PCR (qRT-PCR). RNA was extracted with an RNeasy Mini Kit and CDNA was synthesized with SuperScript III first-strand synthesis system for RT-PCR (both kits are commercial, obtained from Invitrogen). For semi qRT-PCR, $1.5 \mu \mathrm{l}$ of cDNA and $5 \mu \mathrm{l}$ of primers $(10 \mu \mathrm{M})$ were used for one reaction. A total of 20 cycles were run with a C1000 thermal cycler (Bio-Rad, Hercules, CA, USA) and each cycle consisting of denaturation at $94^{\circ} \mathrm{C}$ for $30 \mathrm{~s}$, annealing at $62^{\circ} \mathrm{C}$ for $30 \mathrm{~s}$ and extension at $72^{\circ} \mathrm{C}$ for $1 \mathrm{~min}$. qRT-PCR was run in a $7900 \mathrm{HT}$ fast real-time PCR system with the following cycling conditions: enzyme activation at $95^{\circ} \mathrm{C}$ for $20 \mathrm{~s} ; 40$ cycles for denaturing at $95^{\circ} \mathrm{C}$ for $1 \mathrm{~s}$; and anneal/extend at $60^{\circ} \mathrm{C}$ for $20 \mathrm{~s}$. Finally, $0.25 \mu \mathrm{l}$ of cDNA and $0.2 \mu$ of primers $(10 \mu \mathrm{M})$ in one $10-\mu \mathrm{l}$ reaction were used with Fast SYBR Green Master Mix (Applied Biosystems, Carlsbad, CA, USA). Every reaction was run in triplicate in a 384-well clear optical reaction plate. All the instruments and reagents used for real-time PCR were from Applied Biosystems.

TUNEL assay. TUNEL assays were conducted with an ApopTag Plus Fluorescein In Situ Apoptosis Detection Kit (S7111; EMD Millipore, Billerica, MA, USA) following the indicated protocol. Briefly, cells were treated as indicated, fixed in $1 \%$ paraformaldehyde, washed in PBS three times, incubated in equilibration buffer for $10 \mathrm{~min}$ and incubated with terminal deoxynucleotidyl transferase for $60 \mathrm{~min}$ at $37^{\circ} \mathrm{C}$. Cells were washed with stop buffer for $10 \mathrm{~min}$ and then incubated with anti-digoxigenin conjugate for $30 \mathrm{~min}$ at $25^{\circ} \mathrm{C}$. After washing in PBS, cells were mounted with DAPI and viewed and photographed on a microscope with a fluorescent attachment.

Caspase 3 activity assay. After being exposed to DM with or without CNTs for $24 \mathrm{~h}$, cell lysates were prepared and $200 \mu \mathrm{g}$ of proteins were used for caspase 3 activity assays. Samples were read at $400 \mathrm{~nm}$ in a microtiter plate reader and fold increase in caspase 3 activity was determined by comparing with the level in cells cultured in growth medium.

Co-immunoprecipitation. Cell lysates were extracted with $1 \times$ RIPA Buffer, and $200 \mu \mathrm{g}$ of lysate was used for each immunoprecipitation. Before precipitation 
with primary antibodies, lysate was precleared by adding $1.0 \mu \mathrm{g}$ of the appropriate normal mouse or rabbit IgG (corresponding to the host species of the primary antibody) together with $20 \mu \mathrm{l}$ of resuspended Protein A/G Plus-Agarose. Each precipitation used $1 \mu \mathrm{g}$ of primary antibodies and $20 \mu$ l of Protein A/G plus-agarose. After centrifugation, samples were boiled in $1 \%$ SDS solution and analyzed by western blot. All western blots were imaged with an Odyssey Infrared Imaging System (LI-COR Biosciences).

ChIP assay. ChIP is a method to determine the identity and quantity of DNAs that bind particular proteins of interest. Following the breakage of DNA molecules into pieces by sonication, the protein-DNA complex can be immunoprecipitated out from the cellular lysate by using an antibody that is specific to a putative DNAbinding protein. Then the identity and quantity of DNA bound by the protein can be analyzed using PCR. After optimization of DNA-shearing conditions, the manufacturer's standard protocol for ChIP was followed. About $1 \times 10^{6} \mathrm{C} 2 \mathrm{C} 12$ cells in a $10-\mathrm{cm}$ dish were treated with $1 \%$ formaldehyde for $10 \mathrm{~min}$ at $37^{\circ} \mathrm{C}$. Cells were washed twice with cold PBS containing protease inhibitors and suspended in $200 \mu$ l SDS lysis buffer in a $1.5 \mathrm{ml}$ eppendorf tube, which was then held in ice water. Sonication was applied to the cell pellets for a total of $18 \mathrm{~min}$ using a $130-\mathrm{W}$ ultrasonic processor (model: VCX 130) accessorized with a 6-mm probe (model: CV18) (VWR International Ltd, Hunter Boulevard, England) with the following setting: amplitude setting $15 \%$ using $15 \mathrm{~s}$ pulses with $30 \mathrm{~s}$ cool-down intervals between pulses. About $20 \mu$ of sonicated cell supernatant was kept as input samples and the rest was diluted by 10 -fold. After immunoprecipitation with anti-HEB and antiMyoD antibodies, $60 \mu$ lof protein A agarose/salmon sperm DNA was added for $1 \mathrm{~h}$ of culture, followed by centrifuge. The complex was eluted and histone-DNA crosslinks were reversed by heating at $65^{\circ} \mathrm{C}$ for $4 \mathrm{~h}$. DNA was recovered by phenol/chloroform extraction. Finally, $5 \mu \mathrm{l}$ of DNA suspension was used for PCR cycling.

In situ PLA. Cells were seeded on 35-mm glass-bottom dishes (MatTek Corp., Ashland, MA, USA). After treatment, cells were fixed with cold $4 \%$ paraformaldehyde for $15 \mathrm{~min}$ at room temperature followed by cell-membrane permeabilization with $0.25 \%$ Triton-X-100 in PBS for $10 \mathrm{~min}$. The cells were washed three times with PBS, blocked for $1 \mathrm{~h}$ at room temperature with $1 \% \mathrm{BSA}$ in PBS containing $0.1 \%$ Tween- 20 and incubated with the indicated antibody pairs in a cell incubator at $37^{\circ} \mathrm{C}$. Duolink in situ PLA (Olink Bioscience, Uppsala, Sweden) was performed according to the manufacturer's instructions. Images were taken using an Olympus Research Inverted System Microscope (Olympus, Center Valley, PA, USA) with IX81 LUCplan FLN objectives and cellSen Dimension software (1.4.1; Olympus). The paired primary antibodies used included rabbit and mouse BMP4 antibody, rabbit BMPR1A antibody and rabbit and mouse BMPR2 antibody. For preparation of IgG-conjugated MWCNT 1, mouse IgG $(100 \mu \mathrm{g}$, Santa Cruz Biotechnology, Inc.) or BSA $(100 \mu \mathrm{g})$ was mixed with MWCNT $1(50 \mu \mathrm{l}$ of the supernatant of $0.5 \mathrm{mg} / \mathrm{ml}$ aqueous solution after being centrifuged at $10000 \times g$ for $1 \mathrm{~min}$ ) in water (final volume, $400 \mu \mathrm{l}$ ) and shaken overnight at $4^{\circ} \mathrm{C}$. The mixture was centrifuged at $16000 \times g$ for $30 \mathrm{~min}$ and the pellet was resuspended in $100 \mu \mathrm{l}$ of water. Finally, $50 \mu \mathrm{g} / \mathrm{ml}$-conjugated MWCNT 1 was used for cell treatment $(2 \mathrm{~h})$.

FRET. FRET was performed using a Zeiss LSM 510 Meta microscope with a $\times 63$ oil objective lens, all controlled by Zen 2009 software (Peabody, MA, USA). For labeling MWCNT 1, $200 \mu \mathrm{l}$ of the supernatant of aqueous MWCNT 1 suspension $(0.5 \mathrm{mg} / \mathrm{ml}$, centrifuged at $10000 \times g$ for $1 \mathrm{~min})$ was mixed with $4.2 \mathrm{mg}$ of FITCBSA (Sigma, St. Louis, MO, USA) in $0.6 \mathrm{ml}$ of $\mathrm{ddH}_{2} \mathrm{O}$ and shaken overnight at $4^{\circ} \mathrm{C}$. The mixture was centrifuged at $16000 \times g$ for $30 \mathrm{~min}$ to pellet MWCNT 1 , and the pellet was washed once with PBS. Finally, the pellet was suspended in $0.2 \mathrm{ml}$ of $\mathrm{ddH}_{2} \mathrm{O}$. $\mathrm{C}_{2} \mathrm{C} 12$ cells were seeded on $35-\mathrm{mm}$ glass-bottom dishes (MatTek Corp.). After incubation with FITC-conjugated MWCNT $1(50 \mu \mathrm{g} / \mathrm{ml})$ for $2 \mathrm{~h}$, cells were washed with PBS twice to remove free MWCNT 1. Samples were prepared as for immunocytochemistry. FRET was detected by an acceptor photobleaching method. This method involves measuring the donor de-quenching in the presence of an acceptor. This can be done by comparing donor fluorescence intensity in the same sample before and after destroying the acceptor by photobleaching. If FRET was initially present, a resultant increase in donor fluorescence will occur after photobleaching of the acceptor. A selected region of interest was irradiated with the $543-\mathrm{nm}$ laser line (70\% bleach power, 50 iterations) for $12 \mathrm{~s}$ to photobleach TRITC. FITC and TRITC images were collected immediately after photobleaching, and FRET was measured as an increase in FITC fluorescence intensity. The FRET efficiency was calculated as $\mathrm{FRET}$ eff $=1-D_{\text {pre }} / D_{\text {pos }}$ using the Zen 2009 software, taking into account background noise in each channel, where $D_{\text {pre }}$ and $D_{\text {pos }}$ are, respectively, the even FITC fluorescence intensity in the selected region before and after photobleaching. ${ }^{43}$

Cell transfection and luciferase activity assay. $\mathrm{C} 2 \mathrm{C} 12$ or $\mathrm{C} 33 \mathrm{~A}-2 \mathrm{D} 2$ cells were seeded in 24-well plates. After overnight culture, the cell confluence reached about $80-90 \%$. Next, $0.6 \mu \mathrm{g}$ of plasmids mixed with Lipofectamine 2000 at a ratio $1: 3(\mathrm{w} / \mathrm{v})$ in $100 \mu \mathrm{l}$ of Opti-MEM I Reduced-Serum Medium was used for transfecting cells in one well. A pcDNA3.1 empty vector was used as control for caALK2 and caALK3 constructs and a pGL3 empty vector was used as control for myogenin-luciferase and p21-luciferase constructs. A pGL3 control vector containing SV40 promoter and enhancer sequences was used to monitor the transfection efficiency simultaneously. Six hours after transfection, cells were changed to fresh medium, and $24 \mathrm{~h}$ after transfection, cells were exposed to CNTs. After the indicated time, cell lysates were prepared by adding $80 \mu \mathrm{l}$ of $1 \times$ RIPA buffer to each well. Protein concentration was detected with a BCA Protein Assay Kit (Thermo Scientific, Barrington, IL, USA). A luciferase activity assay was conducted in a white 384-well plate and detected with an Envision 2012 Multilabel Reader (PerkinEImer, Waltham, MA, USA). Finally, $4 \mu \mathrm{l}$ of the lysates and $25 \mu \mathrm{l}$ of Steadylite Plus substrate were used for a one-well assay. The luciferase activity was normalized as luminescence intensity divided by the protein concentration of the same lysate sample.

Id1 promoter activity assay. Approximately 20000 C33A-2D2 cells per well were seeded in white 96-well plates and cultured overnight. Each CNT $(100 \mu \mathrm{g} / \mathrm{ml})$ from the combinatorial array was incubated with cells for $24 \mathrm{~h}$ before BMP4 $(25 \mathrm{ng} / \mathrm{ml})$ was added. After incubation for another $24 \mathrm{~h}, 100 \mu \mathrm{l}$ of Steadylite Plus substrate was added and luminescence intensity was determined. To normalize luciferase activity, a cell viability assay with the same CNT exposure was performed with the XTT method. The luminescence intensity divided by the number of viable cells in each well was used and the value in medium was set as 1 .

Statistical analysis. The two-sided student's $t$-test was used to analyze differences between experiments. Data are reported as mean values \pm S.D. from multiple determinations. $P$-values $<0.05$ were considered statistically significant and all the statistical calculations were carried out using SigmaPlot 10.0 (Systat Software, Chicago, IL, USA).

\section{Conflict of Interest}

The authors declare no conflict of interest.

Acknowledgements. We thank Fu-yue Zeng, Victoria Frohlich, Yannan Ouyang, Sharon Frase, Linda Mann and Jianmin Ye for their technical assistance and Paul B Yu (Harvard Medical School), Michael A Rudnicki (Ottawa Health Research Institute) and Carme Gallego (Universitat de Lleida) for providing constitutive active ALK2 and ALK3 constructs, myogenin-luciferase and p21-luciferase constructs. This work was supported by the National Basic Research Program of China (2010CB933504), National Natural Science Foundation of China (21077068 and 21137002), National Cancer Institute (P30CA027165), NIH (CA096832 and CA21765 for MFR) and the American Lebanese Syrian Associated Charities.

1. Sahoo NG, Bao H, Pan Y, Pal M, Kakran M, Cheng HKF et al. Functionalized carbon nanomaterials as nanocarriers for loading and delivery of a poorly water-soluble anticancer drug: a comparative study. Chem Commun 2011; 47: 5235-5237.

2. Pantarotto D, Singh R, McCarthy D, Erhardt M, Briand J-P, Prato $M$ et al. Functionalized Carbon nanotubes for plasmid DNA gene delivery. Angew Chem Int Edit 2004; 43: 5242-5246

3. Lacerda L, Soundararajan A, Singh R, Pastorin G, Al-Jamal KT, Turton J et al. Dynamic imaging of functionalized multi-walled carbon nanotube systemic circulation and urinary excretion. Adv Mater 2008; 20: 225-230.

4. Holy J, Perkins E, Yu X. Adhesion, proliferation and differentiation of pluripotent stem cells on multi-walled carbon nanotubes. IET Nanobiotechnology 2011; 5: 41-46.

5. Chao T-I, Xiang S, Chen C-S, Chin W-C, Nelson AJ, Wang C et al. Carbon nanotubes promote neuron differentiation from human embryonic stem cells. Biochem Biophys Res Commun 2009; 384: 426-430.

6. Cossu G, Mavilio F. Myogenic stem cells for the therapy of primary myopathies: wishful thinking or therapeutic perspective? J Clin Invest 2000; 105: 1669-1674.

7. Orlic D, Kajstura J, Chimenti S, Jakoniuk I, Anderson SM, Li B et al. Bone marrow cells regenerate infarcted myocardium. Nature 2001; 410: 701-705. 
8. Toma C, Pittenger MF, Cahill KS, Byrne BJ, Kessler PD. Human mesenchymal stem cells differentiate to a cardiomyocyte phenotype in the adult murine heart. Circulation 2002; 105 : 93-98.

9. Kennea NL, Stratou C, Naparus A, Fisk NM, Mehmet H. Functional intrinsic and extrinsic apoptotic pathways in human fetal mesenchymal stem cells. Cell Death Differ 2005; 12: 1439-1441.

10. Mangi AA, Noiseux N, Kong D, He H, Rezvani M, Ingwall JS et al. Mesenchymal stem cells modified with Akt prevent remodeling and restore performance of infarcted hearts. Nat Med 2003; 9: 1195-1201.

11. Amabile G, D'Alise AM, lovino M, Jones P, Santaguida S, Musacchio A et al. The Aurora B kinase activity is required for the maintenance of the differentiated state of murine myoblasts. Cell Death Differ 2008; 16: 321-330.

12. Kagan VE, Tyurina YY, Tyurin VA, Konduru NV, Potapovich Al, Osipov AN et al. Direct and indirect effects of single walled carbon nanotubes on RAW 264.7 macrophages: Role of iron. Toxicol Lett 2006; 165: 88-100.

13. Robinson S, Cho P, Levitsky H, Olson J, Hruban R, Acker M et al. Arterial delivery of genetically labelled skeletal myoblasts to the murine heart: long-term survival and phenotypic modification of implanted myoblasts. Cell Transplant 1996; 5: 77-91.

14. Wang J, Walsh K. Resistance to apoptosis conferred by Cdk inhibitors during myocyte differentiation. Science 1996; 273: 359-361.

15. Hartmann A, Hunot S, Michel PP, Muriel M-P, Vyas S, Faucheux BA et al. Caspase-3: a vulnerability factor and final effector in apoptotic death of dopaminergic neurons in Parkinson's disease. Proc Natl Acad Sci USA 2000; 97: 2875-2880.

16. Parker MH, Perry RLS, Fauteux MC, Berkes CA, Rudnicki MA. MyoD synergizes with the E-protein HEB $\beta$ to induce myogenic differentiation. Mol Cell Biol 2006; 26: 5771-5783.

17. Jen $\mathrm{Y}$, Weintraub $\mathrm{H}$, Benezra $\mathrm{R}$. Overexpression of Id protein inhibits the muscle differentiation program: in vivo association of Id with E2A proteins. Genes Dev 1992; 6 : 1466-1479.

18. Schnapp E, Pistocchi AS, Karampetsou E, Foglia E, Lamia CL, Cotelli F et al. Induced early expression of mrf4 but not myog rescues myogenesis in the myod/myf5 double-morphant zebrafish embryo. J Cell Sci 2009; 122: 481-488.

19. Wang Y, Schnegelsberg PNJ, Dausman J, Jaenisch R. Functional redundancy of the muscle-specific transcription factors Myf5 and myogenin. Nature 1996; 379: 823-825.

20. Andrés V, Walsh K. Myogenin expression, cell cycle withdrawal, and phenotypic differentiation are temporally separable events that precede cell fusion upon myogenesis. J Cell Biol 1996; 132: 657-666.

21. Gartel AL, Tyner AL. The role of the cyclin-dependent kinase inhibitor p21 in apoptosis. Mol Cancer Ther 2002; 1: 639-649.

22. Guo K, Wang J, Andres V, Smith R, Walsh K. MyoD-induced expression of p21 inhibits cyclin-dependent kinase activity upon myocyte terminal differentiation. Mol Cell Biol 1995; 15: 3823-3829.

23. Halevy O, Novitch BG, Spicer DB, Skapek SX, Rhee J, Hannon GJ et al. Correlation of terminal cell cycle arrest of skeletal muscle with induction of p21 by MyoD. Science 1995; 267: 1018-1021.

24. Li C, Tzeng S, Cheng Y, Kang J. Chloramphenicol-induced mitochondrial stress increases p21 Expression and prevents cell apoptosis through a p21-dependent pathway. J Biol Chem 2005; 280: 26193-26199.

25. Suzuki A, Tsutomi Y, Yamamoto N, Shibutani T, Akahane K. Mitochondrial regulation of cell death: mitochondria are essential for procaspase 3-p21 complex formation to resist fasmediated cell death. Mol Cell Biol 1999; 19: 3842-3847.

26. Suzuki A, Ito T, Kawano H, Hayashida M, Hayasaki $Y$, Tsutomi $Y$ et al. Survivin initiates procaspase 3/p21 complex formation as a result of interaction with Cdk4 to resist Fasmediated cell death. Oncogene 2000; 19: 1346-1353.
27. Miyazono K, Miyazawa K. Id: a target of BMP signaling. Sci STKE 2002; 2002: pe40.

28. Mu Q, Du G, Chen T, Zhang B, Yan B. Suppression of human bone morphogenetic protein signaling by carboxylated single-walled carbon nanotubes. ACS Nano 2009; 3: 1139-1144.

29. Liu D, Yi C, Zhang D, Zhang J, Yang M. Inhibition of proliferation and differentiation of mesenchymal stem cells by carboxylated carbon nanotubes. ACS Nano 2010; 4: 2185-2195.

30. Yu PB, Hong CC, Sachidanandan C, Babitt JL, Deng DY, Hoyng SA et al. Dorsomorphin inhibits BMP signals required for embryogenesis and iron metabolism. Nat Chem Biol 2008; 4: 33-41.

31. Anderson GJ, Darshan D. Small-molecule dissection of BMP signaling. Nat Chem Biol 2008; $4: 15-16$

32. Zhu P, Tan Ming J, Huang R-L, Tan Chek K, Chong Han C, Pal M et al. Angiopoietin-like 4 protein elevates the prosurvival intracellular 02:h202 ratio and confers anoikis resistance to tumors. Cancer Cell 2011; 19: 401-415.

33. Noushmehr H, D'Amico E, Farilla L, Hui H, Wawrowsky KA, Mlynarski W et al. Fatty acid translocase (FAT/CD36) is localized on insulin-containing granules in human pancreatic $\beta$-Cells and mediates fatty acid effects on insulin secretion. Diabetes 2005; 54: 472-481.

34. Goedhart J, van Weeren L, Adjobo-Hermans MJW, Elzenaar I, Hink MA, Gadella TWJ Jr. Quantitative co-expression of proteins at the single cell level - application to a multimeric FRET sensor. PLoS One 2011; 6: e27321.

35. Kim BYS, Rutka JT, Chan WCW. Nanomedicine. New Engl J Med 2010; 363. 2434-2443.

36. Verma A, Stellacci F. Effect of surface properties on nanoparticle-cell interactions. Small 2010; 6: 12-21.

37. Zhou H, Mu Q, Gao N, Liu A, Xing Y, Gao S et al. A Nano-combinatorial library strategy for the discovery of nanotubes with reduced protein-binding, cytotoxicity, and immune response. Nano Lett 2008; 8: 859-865.

38. Li W, Sun W, Zhang Y, Wei W, Ambasudhan R, Xia P et al. Rapid induction and long-term self-renewal of primitive neural precursors from human embryonic stem cells by small molecule inhibitors. Proc Natl Acad Sci USA 2011; 108: 8299-8304.

39. Noiseux N, Gnecchi M, Lopez-llasaca M, Zhang L, Solomon SD, Deb A et al. Mesenchymal stem cells overexpressing akt dramatically repair infarcted myocardium and improve cardiac function despite infrequent cellular fusion or differentiation. Mol Ther 2006; 14: 840-850.

40. Zhang L, Webster TJ. Nanotechnology and nanomaterials: promises for improved tissue regeneration. Nano Today 2009; 4: 66-80.

41. Hirano S, Kanno S, Furuyama A. Multi-walled carbon nanotubes injure the plasma membrane of macrophages. Toxicol Appl Pharmacol 2008; 232: 244-251.

42. Mu Q, Liu W, Xing Y, Zhou H, Li Z, Zhang Y et al. Protein binding by functionalized multiwalled carbon nanotubes is governed by the surface chemistry of both parties and the nanotube diameter. J Phys Chem C 2008; 112: 3300-3307.

43. Herrick-Davis K, Weaver BA, Grinde E, Mazurkiewicz JE. Serotonin 5-HT2C receptor homodimer biogenesis in the endoplasmic reticulum. J Biol Chem 2006; 281 27109-27116.

Cell Death and Disease is an open-access journal published by Nature Publishing Group. This work is licensed under the Creative Commons Attribution-NonCommercial-No Derivative Works 3.0 Unported License. To view a copy of this license, visit http://creativecommons.org/licenses/by-nc-nd/3.0/ 